\title{
Stomatal Development and Associated Photosynthetic Characteristics of Watermelon (Citrullus lanatus) Plug Seedlings during Light Storage
}

\author{
Qingqing Duan, Ye Lin, Wu Jiang, and Danfeng Huang ${ }^{1}$ \\ Department of Plant Science, School of Agriculture \& Biology, Shanghai Jiao \\ Tong University, Dongchuan Road 800, Shanghai, 200240, P.R. China; and \\ the Key Laboratory of Urban Agriculture (South), Ministry of Agriculture, P.R. \\ China
}

Additional index words. darkness, light, stomatal density, storage, transplanting, watermelon

\begin{abstract}
Illumination during storage was proven to extend the storability of seedlings, but little attention has been given to the underlying mechanism. To determine how light conditions affect photosynthetic status in watermelon [Citrullus lanatus (Thunb.) Matsum. and Nakai] plug seedlings, differences of stomatal development and relative photosynthetic characteristics of expanding new leaves when stored for 8 days at $15^{\circ} \mathrm{C}$ in light at a photosynthetic photon flux $(P P F)$ of $15 \mu \mathrm{mol} \cdot \mathrm{m}^{-2} \cdot \mathrm{s}^{-1}$ or darkness were investigated. The stomatal density (SD) increased with time to a peak and then decreased from the start of storage in light to the subsequent transplantation. Dark storage retarded the stomatal development and delayed the appearance of the peak of SD. Compared with those under dark storage, light-stored seedlings showed significantly higher SD and stomatal index (SI) in leaves accompanied by higher maximal photochemical efficiency of PSII ( $\left.F_{v} / F_{m}\right)$ and quantum yield of PSII (ФPSII). During storage in darkness, $F_{v} / F_{m}$ and $\Phi$ PSII declined steeply with increasing storage duration but recovered gradually to reach the same level of those in light at the fourth day after transplanting. Seedlings stored in light for 8 days showed higher net photosynthesis rate $(\mathrm{Pn})$, stomatal conductance $\left(g_{\mathrm{S}}\right)$, intercellular $\mathrm{CO}_{2}$ concentration $(\mathrm{Ci})$, and transpiration rate (Tr) than in darkness. The post-storage recovery of $\mathrm{Pn}, g_{\mathrm{S}}$, and $\mathrm{Tr}$ were closely related to the SI, which ensured the fast recovery of photosynthesis during the early stage of transplanting. In agreement with the change of $\mathrm{SD}$, no differences in $\mathrm{Pn}, \mathrm{g}_{\mathrm{S}}, \mathrm{Ci}$, and $\mathrm{Tr}$ between light and dark storage were observed after 8 days of transplantation. Seedlings stored in light appeared vigorous and the shoot dry weight was significantly higher than that of dark-stored ones. Although seedlings in dark storage had a poor appearance during storage, they showed inhibited regrowth potentials during the subsequent transplanting stage. This study exhibited that light in short-term storage contributed to maintaining stomatal development as well as photosynthetic efficiency in watermelon, which could also extend to post-storage for ensuring the transplant quality of seedlings after removal from storage.
\end{abstract}

Watermelon [Citrullus lanatus (Thunb.) Matsum. and Nakai] is an important cucurbit crop, occupying $7 \%$ of the worldwide area allocated for vegetable production (Guo et al., 2013). China, as the largest producer of water-

\footnotetext{
Received for publication 1 Apr. 2014. Accepted for publication 9 May 2014.

This work was supported by funds from the National High-tech Research \& Development Program (Technology research on digital management and precise operation of facility agriculture, No. 2012AA101903), the National agricultural Science-tech Achievements Transformation Project (Vegetable QACCP management and traceability system and its application in the mobile phone software, No. 2012GB2C000142), the National Science-tech Support Plan Project (Research and demonstration of key techniques in industrial production of high quality seedlings, No. 2011BAD43B02), and the Shanghai Graduate Education and Innovation Program (Horticulture). ${ }^{1}$ To whom reprint requests should be addressed; e-mail danfenggrace@gmail.com.
}

(Su et al., 2001) and radiata pine (MenaPetite et al., 2003). Compared with storage, the recovery of post-storage photosynthetic performance is very crucial for plants (Hou et al., 2010; Sato et al., 2004). A positive correlation was obtained after storage between photosynthetic rate and the new root growth in radiata pine seedlings (Mena-Petite et al., 2003). Chlorophyll fluorescence parameters were also closely related to the survival of Douglas fir seedlings in a greenhouse (Harper et al., 2010).

However, stomata, as physiologic channels for photosynthetic gas exchange in plants, which executed an important function in optimizing photosynthetic carbon dioxide $\left(\mathrm{CO}_{2}\right)$ uptake and minimizing transpirational water loss (Chaerle et al., 2005), has not been concerned yet. Many researchers observed a correlation between stomatal density and environmental parameters. Light is one of the important environmental factors regulating the stomatal development in plants (Baroli et al., 2008; Liu et al., 2000). To our knowledge, there has been no study yet reporting on stomatal development of seedlings during storage.

This study investigated the differences in stomatal development during storage under light or dark conditions and the associated photosynthetic performance. Accurately assessing these effects is essential for maintaining watermelon seedling quality during storage and improving the capacity of photosynthetic recovery after removal from storage. These findings will further contribute to our understanding of the physiologic mechanisms of plant growth.

\section{Materials and Methods}

Plant material and growth conditions. Seeds of watermelon [Citrullus lanatus (Thunb.) Matsum. \& Nakai] cv. Zaojia 84-24 were sown in 72 -cell plastic plug trays $\left(50 \mathrm{~cm}^{3}\right.$ per cell) filled with a substrate consisting of vermiculite, perlite, and peat $(2: 2: 1, \mathrm{v} / \mathrm{v} / \mathrm{v})$ in a greenhouse under natural photoperiod and day/nights of $24 / 17 \pm 3{ }^{\circ} \mathrm{C}$. At $20 \mathrm{~d}$ after sowing, uniform seedlings with one fully expanded true leaf and one small true leaf were selected and transferred into growth chambers (Model HP GS1000-D; Wuhan Ruihua Instrument \& Equipment, Co., Ltd., Wuhan, China). The conditions in the growth chambers were as follows: 300 $\mu \mathrm{mol} \cdot \mathrm{m}^{-2} \cdot \mathrm{s}^{-1} P P F$ at 12-h photoperiod, 25/ $18 \pm 2{ }^{\circ} \mathrm{C}$ day/night, and $70 \% \pm 10 \%$ relative humidity. All plants were supplied with half-strength Hoagland solution daily.

Storage and transplant conditions. The storage period began when two true leaves had fully expanded and one small true leaf was expanding. Six plug trays of seedlings were separated into two groups placed in two growth chambers and the air temperature inside chambers was set at $15 \pm 1{ }^{\circ} \mathrm{C}$ (temperature fluctuations in two chambers were similar), which was recommended as the optimal storage temperature of watermelon plug seedlings (Holcomb, 1994). Seedlings were stored for $8 \mathrm{~d}$ in darkness or under light at an average $P P F$ of $15 \pm 0.5 \mu \mathrm{mol} \cdot \mathrm{m}^{-2} \cdot \mathrm{s}^{-1}$. 
The light source during storage was cool white light lamps (Philips Lifemax, TLD $30 \mathrm{w} / 865$ ), which were positioned $\approx 30 \mathrm{~cm}$ above the seedling canopy. The light compensation point is the optimum $P P F$ for lowtemperature storage of seedlings (Kubota et al., 2002). Because there is no recommended light intensity for cucurbit storage reported, the light compensation point for watermelon was estimated as $\approx 15 \mu \mathrm{mol} \cdot \mathrm{m}^{-2} \cdot \mathrm{s}^{-1}$ $P P F$ according to the results reported by Yongjian et al. (2001). There were three trays per treatment, which gave 216 seedlings per treatment. Each tray with 72 seedlings was considered as a replication. Every $2 \mathrm{~d}$, seedling trays were taken from the chambers and subirrigation was applied with the same nutrient solution as that used before storage for 5 min under dim light (less than $1 \mu \mathrm{mol} \cdot \mathrm{m}^{-2} \cdot \mathrm{s}^{-1}$ ) conditions at ambient room temperatures; then trays were relocated among chambers to minimize environmental differences.

After $8 \mathrm{~d}$ of storage, seedlings were transplanted into $20-\mathrm{cm}$ diameter plastic pots and allowed to recover in growth chambers at 25 / $18 \pm 2{ }^{\circ} \mathrm{C}$ (day/night) for $8 \mathrm{~d}$. Seedlings were supplied with half-strength Hoagland's solution once per day.

Seedlings were sampled just before the start of storage $(0 \mathrm{~d}) ; 2,4$, and $8 \mathrm{~d}$ later; and subsequently 2,4 , and $8 \mathrm{~d}$ of transplanting. The third true leaves, which were considered as expanding new leaves, were used for all measurements in this experiment.

Stomatal counting. Epidermis imprints on abaxial leaf from the third true leaves were used to count stomata, and the imprints were removed using transparent adhesive tape and were placed on a microscope slide (Bahareh et al., 2012). The light microscope with a $40 \times$ magnification lenses was used to count the number of stomata and epidermal cells. The counting was replicated on three plants in total 30 fields of view for each treatment during storage and recovery. The obtained values were expressed in number of stomata per $\mathrm{mm}^{2}$. The stomatal index was calculated as $\mathrm{SI}=100 \mathrm{SD} /(\mathrm{SD}+\mathrm{ECD})$ where $\mathrm{SD}$ is stomatal density and ECD is epidermal cells density as defined by Rengifo et al. (2002).

Chlorophyll fluorescence measurements and photosynthetic gas exchange. Chlorophyll fluorescence parameters were monitored using a portable modulated chlorophyll fluorometer (FMS-2; Hansatech, Norfolk, U.K.). The initial fluorescence $\left(\mathrm{F}_{\mathrm{o}}\right)$ and maximal fluorescence $\left(\mathrm{F}_{\mathrm{m}}\right)$ were measured after dark adaptation for $30 \mathrm{~min}$. The maximal photochemical efficiency of PSII $\left(\mathrm{F}_{\mathrm{v}} / \mathrm{F}_{\mathrm{m}}\right)$ was calculated as $\mathrm{F}_{\mathrm{v}} / \mathrm{F}_{\mathrm{m}}=\left(\mathrm{F}_{\mathrm{m}}-\mathrm{F}_{\mathrm{o}}\right) / \mathrm{F}_{\mathrm{m}}$. During illumination, the steady-state fluorescence $\left(\mathrm{F}_{\mathrm{s}}\right)$ was obtained. The light-adapted maximum fluorescence $\left(\mathrm{F}_{\mathrm{m}}{ }^{\prime}\right)$ was also determined by applying a saturating pulse at 8000 $\mu \mathrm{mol} \cdot \mathrm{m}^{-2} \cdot \mathrm{s}^{-1}(P P F)$. The ФPSII was calculated according to the method described previously (Van and Snel, 1990). Six plants from each treatment were measured.

The $\mathrm{Pn}, g_{\mathrm{S}}, \mathrm{Ci}$, and $\mathrm{Tr}$ were measured using a Ciras-2 portable photosynthesis system (PP Systems, Amesbury, MA) with a light- emitting diode light source at $800 \mu \mathrm{mol} \cdot \mathrm{m}^{-2} \cdot \mathrm{s}^{-1}$ $(P P F)$. The leaf area clipped by the chamber was $1.7 \mathrm{~cm}^{2}$. The temperature, relative humidity, and $\mathrm{CO}_{2}$ concentration for measurement were maintained at $25{ }^{\circ} \mathrm{C}, 45 \% \pm 5 \%$, and $375 \mu \mathrm{mol} \cdot \mathrm{mol}^{-1}$, respectively. The measurements were from at least three plants for each treatment.

Plant growth parameters and tissue biomass. Nine plants from each treatment were sampled. Sampled plants were washed carefully to remove the medium and the shoots were cut from plants. The washing procedure was carried out at room temperature within a few minutes for each plant. Then the third true leaves were cut from shoots; after that, the leaves were scanned using an Epson Perfection V700 Photo scanner (Japan) to determine the leaf area by WinRHIZO Pro software (Regent Instruments, Canada); subsequently, the leaves and the other part of shoots were dried at $80{ }^{\circ} \mathrm{C}$ for $48 \mathrm{~h}$ in folded paper envelopes to obtain shoot dry weight.

Statistical analysis. The experiment was conducted three times; similar trends were observed in the three repetitions of this experiment, and the data obtained with the third repetition are presented subsequently. All the statistical analysis was performed using SPSS 16.0 for Windows (SPSS, Chicago, IL). Data were subjected to analysis of variance and mean values were compared by the Tukey test $(P<0.05)$ when a significant difference was detected.

\section{Results and Discussion}

Stomatal characteristics. Stomatal initiation is most active in the early development of the leaf, which was observed within $3 \mathrm{~d}$ of a change in light intensity (Gay and Hurd, 1975). In this test, significantly higher SD in plants under light than those under darkness was observed at $2 \mathrm{~d}$ after storage (Fig. 1A), which indicated that stomatal development was delayed by dark storage. Seedlings stored for $8 \mathrm{~d}$ in darkness showed more small unfledged stomata including meristemoid and guard mother cells on the epidermis of leaves than those in light (Fig. 2A-B). Increase in SD associated with leaf expansion and subsequent decrease in SD after SD peak was reached have been widely reported in several plant species (Fu et al., 2010; Gay and Hurd, 1975; Turner and Heichel, 1977). In this test, the peak SD of the plants stored in light appeared at $2 \mathrm{~d}$ after transplanting, then decreased with time, whereas the SD continuously increased in the plants stored in darkness during the experiment (i.e., storage and transplanting). These data indicated the inhibition of stomatal development in leaves caused by dark storage. Similar results were also observed in cotyledons of dark-grown wild-type Arabidopsis (Kang et al., 2009).

$\mathrm{SD}$ at the end of the transplanting period was the same between light- and dark-stored plants (Fig. 1A), but the epidermal cell density (ECD) was significantly lower in light than in darkness (Fig. 1C), which could largely be explained by the increase in epidermal cell expansion (Fig. 2C-D) and by the enlargement of the leaf area in light (Fig. 1D). The plants in light and dark storage exhibited different trends in their SI. SI increased gradually during storage in light but decreased with time during dark storage (Fig. 1B). After removal from storage, SI of

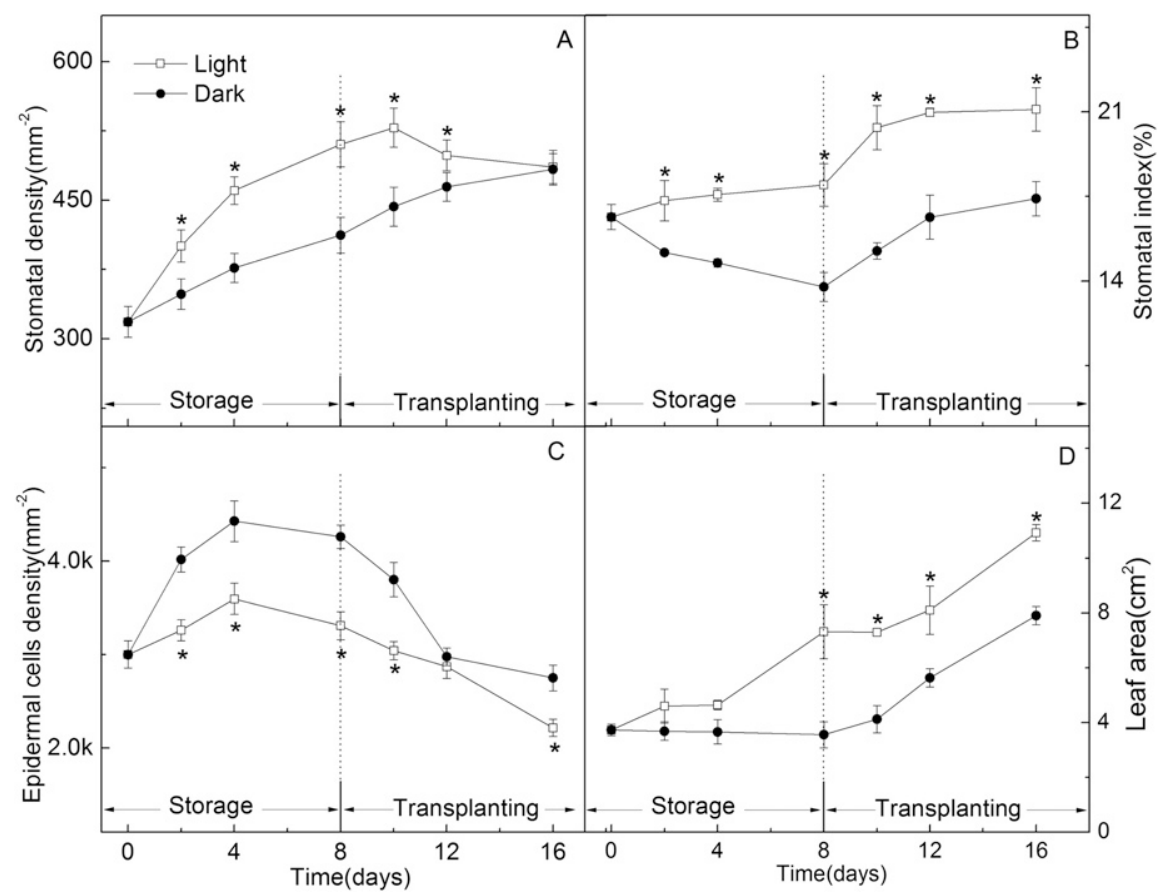

Fig. 1. Changes in stomatal density (A), stomatal index (B), epidermal cells density (C), and leaf area (D) of expanding new leaves of watermelon (Citrullus lanatus) seedlings in light ( $\square$ ) and dark (•) during storage at $15^{\circ} \mathrm{C}$ and subsequent transplanting. Data of $\mathbf{A}, \mathbf{B}$, and $\mathbf{C}$ are the means of 30 replicates and $\mathbf{D}$ are the means of nine replicates with SES shown by the vertical bar. Asterisk indicates significant difference between treatments on a given day according to Tukey test $(P<0.05)$. 


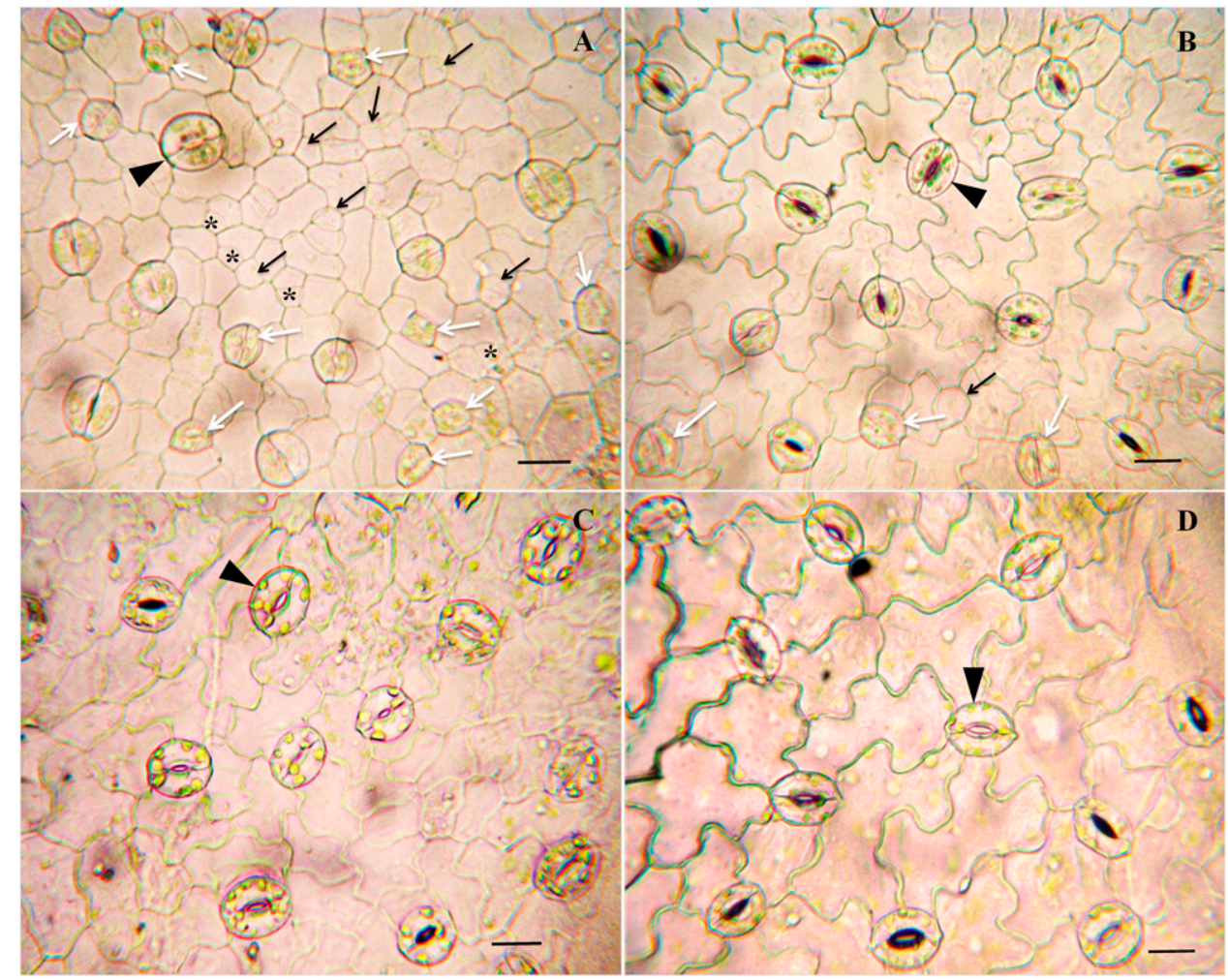

Fig. 2. Effects of storage and recovery on leaf epidermal structure of watermelon (Citrullus lanatus) seedlings using a light microscope. Stomata and epidermal cells on the abaxial leaf epidermis stored for $8 \mathrm{~d}$ in darkness $(\mathbf{A})$ and light $(\mathbf{B})$ and post-storage for $8 \mathrm{~d}$ from darkness $(\mathbf{C})$ and light $(\mathbf{D})$ storage. Black asterisk, black arrowhead, white arrowhead, and black arrow indicate the meristemoid, guard mother cells, guard cells, and mature stomata, respectively. Bar $=15 \mu \mathrm{m}$.

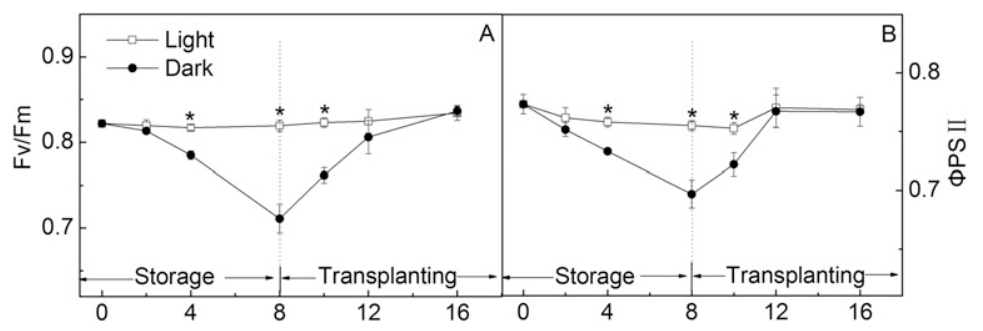

Fig. 3. Changes in maximal photochemical efficiency of PSII $\left(\mathrm{F}_{\mathrm{v}} / \mathrm{F}_{\mathrm{m}}\right)(\mathbf{A})$ and quantum yield of PSII (ФPSII) (B) of watermelon (Citrullus lanatus) leaves in light ( $\square$ ) and dark $(\bullet)$ during storage at $15^{\circ} \mathrm{C}$ and subsequent transplanting. Data are the means of six replicates with SEs shown by the vertical bar. Asterisk indicates significant difference between treatments on a given day according to Tukey test $(P<0.05)$.

two treatments initially increased quickly and then was stably maintained, but the plants under light storage showed pronounced higher SI throughout the experiment than those under dark storage. SD is influenced by epidermal cell size, and SI directly measures the proportion of epidermal cells that differentiated into stomata, which is modified by light intensity (Ferris et al., 2002). In the current data, the SI reduction in leaves from the dark treatment was mainly caused by the increase in ECD (Fig. 1C).

Chlorophyll fluorescence measurements. $\mathrm{F}_{\mathrm{v}} / \mathrm{F}_{\mathrm{m}}$ was usually used to estimate the degree of photoinhibition (Tezara et al., 2005). As shown in Figure 3A, the plants stored in light maintained high $\mathrm{F}_{\mathrm{v}} / \mathrm{F}_{\mathrm{m}}$ values, whereas the $\mathrm{F}_{\mathrm{v}} / \mathrm{F}_{\mathrm{m}}$ continuously decreased during $8 \mathrm{~d}$ of dark storage, which was throughout lower than in light. After $4 \mathrm{~d}$ of post-storage, $\mathrm{F}_{\mathrm{v}} / \mathrm{F}_{\mathrm{m}}$ from two treatments reached the same level and were not different from those before storage. These results showed that there was no photoinhibition of the plants in light storage; however, slight and reversible photoinhibition occurred in dark storage.

Unlike the $F_{v} / F_{m}$, storage induced the decrease in $\Phi P S I I$ regardless of light conditions (Fig. 3B), and the reduction of $\Phi$ PSII during storage was more pronounced in dark than in light. The decline in ФPSII was accompanied by similar decreases in both photochemical quenching coefficient and efficiency of excitation energy capture by open PSII reaction centers $\left(\mathrm{F}_{\mathrm{v}}{ }^{\prime} / \mathrm{F}_{\mathrm{m}}{ }^{\prime}\right)$ (data not shown), which confirmed the reduced linear electron passage through PSII during storage. However, no difference was obtained in ФPSII from two treatments as well as in $\mathrm{F}_{\mathrm{v}} / \mathrm{F}_{\mathrm{m}}$ after $4 \mathrm{~d}$ of transplanting.

$\mathrm{F}_{\mathrm{v}} / \mathrm{F}_{\mathrm{m}}$ and $\Phi$ PSII were widely used as effective indicators for a variety of seedlings of conifers during storage and closely related to the survival of post-storage seedlings (L'Hirondelle et al., 2007; Maki and Colombo, 2001). As shown in Figure $3\left(\mathrm{~F}_{\mathrm{v}} / \mathrm{F}_{\mathrm{m}}\right.$ and ФPSII), the damage extent to PSII reaction center in light-stored seedlings was less than that of dark-stored ones, which suggests that a temporary and reversible decrease of PSII photochemical activity plays an indispensable photoprotective function during storage.

Carbon assimilation and dry mass accumulation. One important reason for better quality of seedlings stored in light mainly the result of the preservation of the photosynthetic ability (Kubota and Kozai, 1994; Mena-Petite et al., 2003), which would ensure the transplant quality of post-storage seedlings effectively (Hou et al., 2010; Sato et al., 2004). As shown in Figure 4, plants stored in light showed a marked high value in Pn accompanied by higher $g_{\mathrm{S}}, \mathrm{Ci}$, and $\mathrm{Tr}$ than in darkness after $8 \mathrm{~d}$ of storage, which is in agreement with the changes in $F_{v} / F_{m}$ and ФPSII. This result demonstrated the preservation of photosynthetic capabilities in light during storage, which ensured the quick recovery of post-storage photosynthesis during the early stage of transplanting. On the fourth day after removal from storage, seedlings stored in light showed higher $\mathrm{Pn}, g_{\mathrm{S}}, \mathrm{Ci}$, and $\mathrm{Tr}$ than that of dark-stored ones (Fig. 4). However, no differences were observed between 
two treatments after $8 \mathrm{~d}$ of transplantation, which were consistent with the change in SD (Fig. 1A).

In principle, an increase in SD could allow plants under well-adapted conditions to increase conductance for gas exchange at the leaf surface and thus avoid photosynthetic limitation by suboptimal $\mathrm{CO}_{2}$ supply (Schlüter et al., 2003). A close relation between the number of stomata and the increase of leaf photosynthesis has been found in many species (Das and Ghose, 2005; Fu et al., 2010; Lee et al., 2007). In this test, seedlings stored in light showed higher SD and SI in leaves accompanied by higher $\mathrm{F}_{\mathrm{v}} / \mathrm{F}_{\mathrm{m}}$, ФPSII, Pn, $g_{\mathrm{S}}$, $\mathrm{Ci}$, and $\mathrm{Tr}$ during storage than that of darkstored ones, and also, the post-storage $\mathrm{Pn}, g_{\mathrm{S}}$, and $\mathrm{Tr}$ closely related to SI in leaves (Fig. 5). These data indicated that the preservation of photosynthetic capacity of light-stored seedlings might be attributed to the higher SD and SI of leaves under light, which led to favorable stomatal aperture and thus increased the amount of $\mathrm{CO}_{2}$ in the interior of cells to avoid the decrease of photosynthesis by stomatal limitation during storage and the subsequent recovery period.

Dry mass is an important factor in plant storage because it indicates how environmental conditions affect growth rate and dry mass accumulation (Justus and Kubota, 2010). Illumination during storage was proven to preserve the dry weight of seedlings of horticultural crops (Kubota et al., 2002; Wilson et al., 1998a). As shown in Figure 6, seedlings stored in darkness for $8 \mathrm{~d}$ had significantly lower shoot dry weight than those stored in light, which is the result of the continuous respiration that occurred in darkness. Plants stored in light for $8 \mathrm{~d}$ appeared vigorous and similar to the plants before storage. All the seedlings stored in light survived, whereas seedlings stored in darkness deteriorated by some necrosis or chlorosis on old leaves or cotyledons, which resulted in 35\% death of seedlings after transplanting (data not shown). The shoot dry weight (Fig. 6) of seedlings stored in darkness was obviously lower than that of seedlings stored in light throughout the period of recovery in this experiment, which indicated that the deterioration of seedlings stored in darkness significantly suppressed the early growth of seedlings after storage.

$S$ previous study showed that light-stored seedlings maintained high chlorophyll content (Kubota et al., 2002; Wilson et al., 1998a) and carbohydrate reserve (Wilson et al., 1998b), which could be beneficial for maintaining high photosynthetic rate and faster recovery after transplanting (Ding et al., 2011). Despite these, the current data in this experiment showed the possible reasons for better quality in light-stored watermelon seedlings: 1) the promotion of stomatal development in leaves during light storage with better stomata morphology and higher SD and SI contributed to photosynthesis; 2) higher photochemical activities of PSII in seedlings of light storage reduced the damage extent of PSII reaction center and protected the photosynthetic system during storage; and

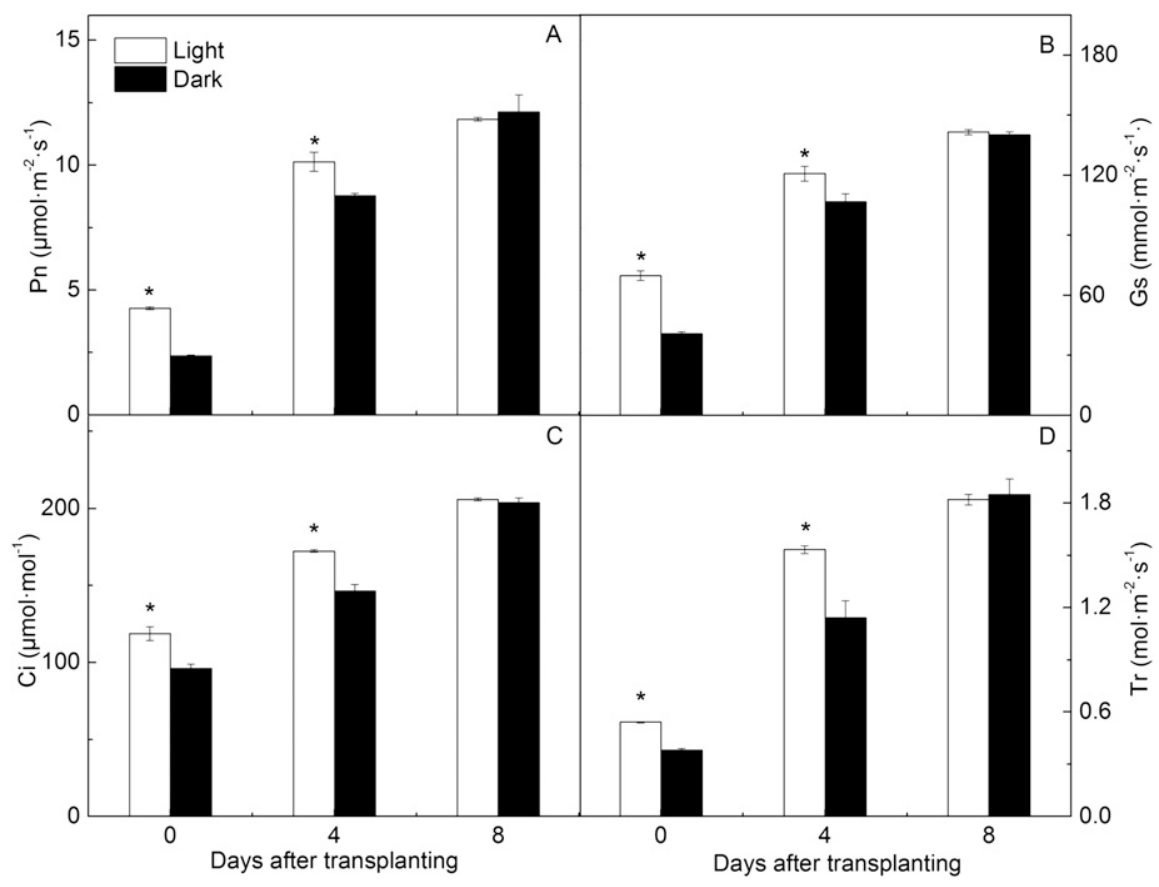

Fig. 4. Net photosynthesis rate $(\mathrm{Pn})(\mathbf{A})$, stomatal conductance $\left(g_{\mathrm{S}}\right)(\mathbf{B})$, intercellular $\mathrm{CO}_{2}$ concentration (Ci) (C), and transpiration rate (Tr) (D) of watermelon (Citrullus lanatus) leaves after $8 \mathrm{~d}$ of transplanting affected by light $(\square)$ and dark $(\square)$ storage at $15{ }^{\circ} \mathrm{C}$. Asterisk indicates significant difference between treatments on a given day according to Tukey test $(P<0.05)$.

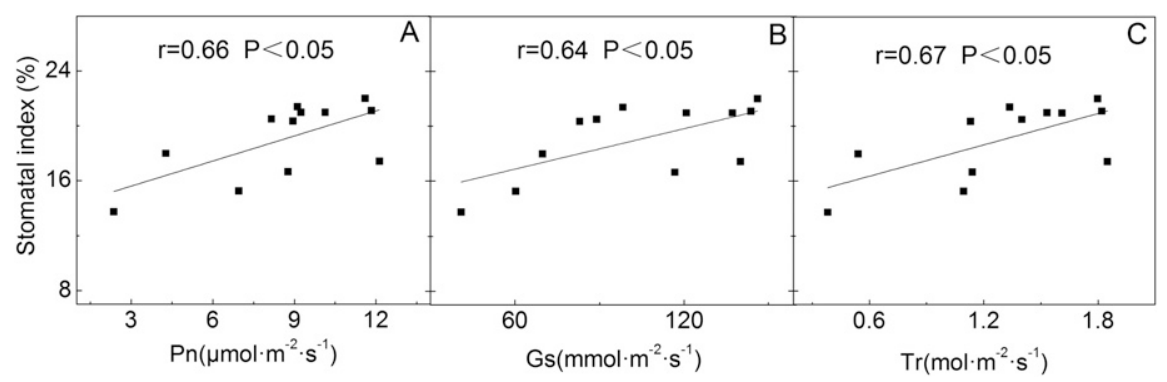

Fig. 5. Relationships between stomatal index and net photosynthesis rate $(\mathrm{Pn})(\mathbf{A})$, stomatal conductance $\left(g_{\mathrm{S}}\right)(\mathbf{B})$, and transpiration rate $(\mathrm{Tr})(\mathbf{C})$ of the expanding new leaves in watermelon (Citrullus lanatus) seedlings after transplanting. Data are from $0,2,4$, and $8 \mathrm{~d}$ of post-storage after light and dark storage at $15^{\circ} \mathrm{C}$ and non-storage. Correlation coefficients $(r)$ and the levels of significance $(P)$ are shown on the panels.

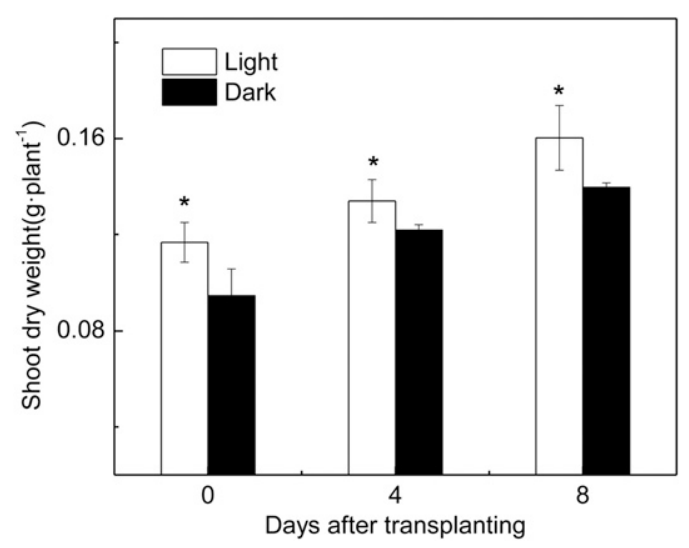

Fig. 6. Shoot dry weight of watermelon (Citrullus lanatus) seedlings after $8 \mathrm{~d}$ of transplanting affected by light $(\square)$ and dark ( $)$ storage at $15^{\circ} \mathrm{C}$. Data are the means of nine replicates with sEs shown by the vertical bar. Asterisk indicates significant difference respectively between treatments on a given day according to Tukey test $(P<0.05)$. 
3) favorable appearance and vigor of seedlings in light storage dedicated to the preservation of dry weight during storage and regrowth potentials after transplanting.

In conclusion, the stomata of watermelon plug seedlings stored in light developed well in morphology with higher SD and SI, which seemed to improve the physiological functions showing significantly higher $\mathrm{Pn}, g_{\mathrm{S}}, \mathrm{Ci}$, and $\mathrm{Tr}$ than in darkness not only during storage, but also after transplanting (until the eighth day). Furthermore, seedlings stored in light showed obvious higher shoot dry mass than in darkness during the entire recovery period. This study exhibited that light in short-term storage contributed to maintaining stomatal development as well as photosynthetic efficiency in watermelon, and this benefit could also extend to the early stage of post-storage for ensuring the transplant quality of seedlings after removal from storage.

\section{Literature Cited}

Bahareh, K., T.A. Seyed Reza, M. Mohammad, M. Amir, and J. Aliashraf. 2012. Some physiological and enzymatic characterizations of Damask Rose accessions (Rosa damascena Mill.). Aust. J. Crop. Sci. 6:283-290.

Baroli, I., G.D. Price, M.R. Badger, and S. Caemmerer. 2008. The contribution of photosynthesis to the red light response of stomatal conductance. Plant Physiol. 146:737-747.

Chaerle, L., N. Saibo, and D. Van Der Straeten. 2005. Tuning the pores: Towards engineering plants for improved water use efficiency. Trends Biotechnol. 23:308-315.

Das, S. and M. Ghose. 2005. Relation of leaf micromorphology with photosynthesis and water efflux in some Indian mangroves. Acta Bot. Croat. 64:331-340.

Ding, M., B. Bie, W. Jiang, Q. Duan, H. Du, and D. Huang. 2011. Physiological advantages of grafted watermelon (Citrullus lanatus) seedlings under low-temperature storage in darkness. HortScience 46:993-996.

Ferris, R., L. Long, S.M. Bunn, K.M. Robinson, H.D. Bradshaw, A.M. Rae, and G. Taylor. 2002. Leaf stomatal and epidermal cell development: Identification of putative quantitative trait loci in relation to elevated carbon dioxide concentration in poplar. Tree Physiol. 22:633-640.

Fu, Q.S., B. Zhao, Y.J. Wang, S. Ren, and Y.D. Guo. 2010. Stomatal development and associated photosynthetic performance of capsicum in response to differential light availabilities. Photosynthetica 48:189-198.
Gay, A.P. and R.G. Hurd. 1975. The influence of light on stomatal density in the tomato. New Phytol. 75:37-46.

Guo, S., J. Zhang, H. Sun, J. Salse, W.J. Lucas, H. Zhang, Y. Zheng, L. Mao, Y. Ren, and Z. Wang. 2013. The draft genome of watermelon (Citrullus lanatus) and resequencing of 20 diverse accessions. Nat. Genet. 45:5158

Harper, R.C., C. O'Reilly, and M. Perks. 2010. Rapidly detecting the effects of warm storage stress on Douglas fir seedlings. Plant Biosyst. 144:769-777.

Holcomb, E.J. 1994. Bedding plants IV. 4th Ed. Ball Publishing, Batavia, IL.

Hou, J.Y., T.L. Setter, and Y. Chang. 2010. Effects of simulated dark shipping on photosynthetic status and post-shipping performance in $\mathrm{Pha}$ laenopsis Sogo Yukidian 'V3'. J. Amer. Soc. Hort. Sci. 135:183-190.

Justus, I. and C. Kubota. 2010. Effects of low temperature storage on growth and transplant quality of non-grafted and grafted cantaloupetype muskmelon seedlings. Sci. Hort. 125:47-54

Kaczperski, M.P., A.M. Armitage, and P.M. Lewis 1996. Performance of plug-grown geranium seedlings preconditioned with nitrogen fertilizer or low-temperature storage. HortScience 31:361-363.

Kang, C., H.L. Lian, F.F. Wang, J.R. Huang, and H.Q. Yang. 2009. Cryptochromes, phytochromes, and COP1 regulate light-controlled stomatal development in Arabidopsis. The Plant Cell Online. 21:2624-2641.

Kubota, C. and T. Kozai. 1994. Low-temperature storage for quality preservation and growth suppression of broccoli plantlets cultured photoautotrophically in vitro. HortScience 29:11911194.

Kubota, C., S. Seiyama, and T. Kozai. 2002. Manipulation of photoperiod and light intensity in low-temperature storage of eggplant plug seedlings. Sci. Hort. 94:13-20.

Lee, S.H., R.K. Tewari, E.J. Hahn, and K.Y. Paek. 2007. Photon flux density and light quality induce changes in growth, stomatal development, photosynthesis and transpiration of Withania Somnifera (L.) Dunal. plantlets. Plant Cell Tiss. Org. 90:141-151.

L'Hirondelle, S.J., D.G. Simpson, and W.D. Binder. 2007. Chlorophyll fluorescence, root growth potential, and stomatal conductance as estimates of field performance potential in conifer seedlings. New For. 34:235-251.

Liu, G.L., S.J. Britz, and W.P. Wergin. 2000. Blue light inhibits stomatal development in soybean isolines containing kaempferol-3-O-2 ${ }^{\mathrm{G}}$-glycosylgentiobioside (K9), a unique flavanoid glycoside. Plant Cell Environ. 23:883-891.

Maki, D.S. and S.J. Colombo. 2001. Early detection of the effects of warm storage on conifer seedlings using physiological tests. For. Ecol. Mgt. 154:237-249.

Mena-Petite, A., A. Robredo, S. Alcalde, M.K. Dunabeitia, M.B. Gonzalez-Moro, M. Lacuesta, and A. Munoz-Rueda. 2003. Gas exchange and chlorophyll fluorescence responses of Pinus radiata D. Don seedlings during and after several storage regimes and their effects on postplanting survival. Trees Struct. Funct. 17:133143.

Park, J.S. and K. Fujiwara. 2009. Quality preservation of tomato seedlings affected by different wavelengths of LED-low light during storage. Eur. J. Hort. Sci. 74:21-23.

Rengifo, E., R. Urich, and A. Herrera. 2002. Water relations and leaf anatomy of the tropical species, Jatropha gossypifolia and Alternanthera crucis, grown under elevated $\mathrm{CO}_{2}$ concentration. Photosynthetica 40:397-403.

Sato, F., H. Yoshioka, T. Fujiwara, H. Higashio, A. Uragami, and S. Tokuda. 2004. Physiological responses of cabbage plug seedlings to water stress during low-temperature storage in darkness. Sci. Hort. 101:349-357.

Schlüter, U., M. Muschak, D. Berger, and T. Altmann. 2003. Photosynthetic performance of an Arabidopsis mutant with elevated stomatal density (sdd1-1) under different light regimes. J. Expt. Bot. 54:867-874.

Su, V., B.D. Hsu, and W.H. Chen. 2001. The photosynthetic activities of bare rooted Phalaenopsis during storage. Sci. Hort. 87:311-318.

Tezara, W., O. Marín, E. Rengifo, D. Martínez, and A. Herrera. 2005. Photosynthesis and photoinhibition in two xerophytic shrubs during drought. Photosynthetica 43:37-45.

Turner, N.C. and G.H. Heichel. 1977. Stomatal development and seasonal changes in diffusive resistance of primary and regrowth foliage of red oak (Quercus rubra L.) and red maple (Acer rubrum L.). New Phytol. 78:71-81.

Van, K.O. and J.F.H. Snel. 1990. The use of chlorophyll fluorescence nomenclature in plant stress physiology. Photosynth. Res. 25:147150.

Wilson, S.B., K. Iwabuchi, N.C. Rajapakse, and R.E. Young. 1998a. Responses of broccoli seedlings to light quality during low-temperature storage in vitro: I. Morphology and survival. HortScience 33:1253-1257.

Wilson, S.B., K. Iwabuchi, N.C. Rajapakse, and R.E. Young. 1998b. Responses of broccoli seedlings to light quality during low-temperature storage in vitro: II. Sugar content and photosynthetic efficiency. HortScience 33:1258-1261.

Yongjian, W., Z. Haiying, Z. Feng, X. Yong, C. Wanhong, and K. Guobin. 2001. Effects of low temperature and low light intensity stress on photosynthesis in seedlings of different cucumber varieties. Acta Horticulturae Sinica 28:230 234 [in Chinese with English abstract]. 